\title{
dosalgarves
}

\section{O papel da imagem dos eventos culturais na construção da marca de um destino turístico: $O$ caso do evento "Braga Romana"}

\section{The role of cultural events image in the construction of the touristic destination brand: "Braga Romana" case study}

\author{
Mário Rola \\ Instituto Politécnico do Cávado e Ave (IPCA), Portugal \\ rola.mario@gmail.com
}

Alexandra Malheiro

Instituto Politécnico do Cávado e Ave (IPCA), UNIAG and CiTUR, Portugal

amalheiro@ipca.pt

Bruno Sousa

Instituto Politécnico do Cávado e Ave (IPCA), UNIAG and CiTUR, Portugal

bsousa@ipca.pt

\begin{abstract}
Resumo
O principal objetivo do presente estudo é perceber qual o papel dos eventos culturais na construção da marca, imagem e qualidade percebida acerca de um destino, aplicado ao caso concreto do evento "Braga Romana" na cidade de Braga. Foi conduzida uma investigação de natureza qualitativa e quantitativa por forma a compreender qual a visão dos responsáveis pelas áreas objeto de estudo, turismo e eventos, e a perceção dos visitantes do evento. Os resultados indicam que os eventos culturais, e concretamente no caso de estudo o evento "Braga Romana" no destino Braga, desempenham um papel determinante no território. Verifica-se, assim, o contributo desta investigação numa perspetiva interdisciplinar, a saber: para o marketing, para o turismo e numa ótica de desenvolvimento local.
\end{abstract}

Palavras-chave: Imagem; marca; eventos culturais; marketing das cidades.

\begin{abstract}
The main objective of this study is to understand the role of cultural events in the construction of the brand, image and perceived quality of a destination, applied to the specific case of the "Braga Romana" event in the city of Braga. A study of a qualitative and quantitative nature was conducted in order to understand the vision of those responsible for the areas studied, tourism and events, and the perception of visitors to the event. The results indicate that cultural events, and specifically in the case of the event "Braga Romana" in the destination of Braga, play a determining role in the territory. Thus, the study makes a contribution from an interdisciplinary perspective, namely: for marketing, tourism and local development.
\end{abstract}

Keywords: Image; brand; cultural events; city marketing.

Dos Algarves: A Multidisciplinary e-Journal, 33-2018.

ISBN 2182-5580 ๑ ESGHT - University of the Algarve, Portugal.

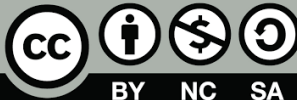

To cite this article: Rola, M., Malheiro, A. \& Sousa, B. (2018). O papel da imagem dos eventos culturais na construção da marca de um destino turístico: O caso do evento "Braga Romana". Dos Algarves: A Multidisciplinary e-Journal, 33, 1-21. doi: 10.18089/DAMeJ.2018.33.1 


\section{Introdução}

As ferramentas de marketing são cada vez mais importantes na gestão e promoção de um produto, marca ou destino, assumindo-se a sua boa utilização como fator de sucesso ou insucesso de uma empresa/destino turístico. A vertente cultural das cidades tem sido um vetor preponderante para a construção e reconstrução das respetivas marcas distintivas (Guerreiro, 2008). Assim, uma marca turística pode ser entendida como um sinal que tem como função primordial identificar, assinalar e designar um lugar como destino turístico (Santos, Carvalho \& Figueira, 2012). Por conseguinte, os eventos culturais assumem-se como ferramentas estratégicas na gestão dos territórios, contribuindo para a construção da oferta turística dos destinos e, consequentemente, para o desenvolvimento cultural, social e económico melhorando a imagem turística dos territórios (Santos et al., 2012). No mesmo sentido, Ribeiro, Vareiro, Fabeiro e de Blas (2005) afirmam que a celebração destes eventos proporciona a criação de uma imagem do destino podendo ter efeitos positivos na imagem externa e interna de um território. Torna-se, assim, importante que se identifique e construa uma identidade dos destinos turísticos assente nos seus recursos culturais distintivos para que se assegure o sucesso da marca e do marketing do lugar (Bianchini \& Ghilardi, 2007).

Para Dimanche (2008), o que torna os eventos uma estratégia-chave para os destinos obterem uma vantagem competitiva em relação aos seus concorrentes é a sua poderosa dupla ação, ou seja, funcionam como criadores de imagem para o destino e como criadores de experiências para os visitantes. O evento Braga Romana - Reviver Bracara Augusta consiste na recriação do quotidiano da cidade há dois mil anos atrás, ou seja, reviver os costumes e tradições de quando esta foi fundada por César Augusto. Esta iniciativa é parte integrante da estratégia de recuperação da História e do Património de Bracara Augusta, possibilitando a divulgação do valioso património romano da Cidade.

Por conseguinte, é fundamental fazer um estudo empírico exaustivo para fundamentar em termos teóricos o contributo dos eventos culturais para a construção da marca e imagem de um destino turístico e no caso prático analisar o papel da imagem do evento Braga Romana na construção da marca e imagem da marca da cidade de Braga. Para tal optou-se por uma abordagem que combina as duas perspetivas: a qualitativa através da administração de duas entrevistas, uma à vereadora da cultura da cidade de Braga e outra ao vereador do turismo, e a quantitativa através da aplicação de um inquérito por questionário aos visitantes do evento Braga Romana, durante o período em que decorreu. A presente investigação está estruturada em seis partes. Após a introdução apresentamos uma breve revisão da literatura. Na terceira, descrevemos sucintamente o evento em estudo. Seguidamente explicamos a metodologia usada e na quinta parte analisamos os resultados alcançados. Por fim, na sexta parte, expomos as conclusões e recomendações.

\section{O marketing das cidades}

Os lugares/cidades têm tido ao longo dos tempos a necessidade de se diferenciar entre si de forma a afirmar a sua individualidade e características distintivas na prossecução dos seus objetivos. Moldar a identidade dos lugares e promovê-la nos mercados, quer internos quer externos, é um paradigma para o qual os governantes já estão despertos (Kavaratzis \& Ashworth, 2008). Esta necessidade de se diferenciarem e criarem imagens positivas urge como forma de obtenção de vantagens competitivas face aos destinos concorrentes (De Carlo, 
Canali, Pritchard \& Morgan, 2009), tornando-se assim o city marketing uma ferramenta fulcral (García, 2009).

Para Morales e Vela (2009), o city marketing é o processo de criação ou transformação da imagem de uma cidade por forma a torná-la desejável para o exterior. Ou seja, segundo estes autores, este conceito define, por um lado, um processo de construção e implementação de uma marca cidade e, por outro, um mecanismo de consolidação da identidade territorial de uma cidade. A visão de García (2009) vai ao encontro do defendido no parágrafo anterior, já que para esta autora, o city marketing é um meio de as cidades promoverem a sua imagem enfatizando determinados aspetos da cultura e pontos de interesse do local suscetíveis de despertar o "desejo" de visita, no potencial turista.

O marketing das cidades pode, assim, ser utilizado ao serviço da conceção, gestão e promoção dos lugares com o objetivo de aumentar a atratividade junto dos diferentes públicos (Gaio \& Gouveia, 2007). Contudo, a sua aplicação está largamente dependente da construção, comunicação e gestão da imagem da cidade (Kavaratzis, 2004; Kavaratzis \& Ashworth, 2005). Para Azevedo, Magalhães e Pereira (2011), o marketing de cidades deve ser usado para a formulação da marca cidade, para a promover e manter atualizada através da criação e difusão de uma imagem urbana positiva, construída com base nos elementos identitários do local.

A gestão da marca territorial proporciona diversas vantagens ao nível do desenvolvimento sustentável de um destino turístico, estimulando as exportações e atraindo mais turismo e investimento. Tal como as empresas, também as cidades e os países podem (e devem) desenvolver as suas próprias marcas, tornando-se destinos cada vez mais diferenciadores e competitivos (Moilanen \& Rainisto, 2009; Fetscherin, 2010; Sousa \& Simões, 2010; Sousa \& Vasconcelos, 2018). De acordo com Kavaratzis e Ashworth (2008), a prática do marketing de lugares desenvolveu-se, ao longo do tempo, e foi registando diversas fases. Estas etapas não seguem uma linha de tempo específica, ou um espaço geográfico distintivo. Neste contexto, atinge-se um marketing de lugares segmentado, com públicos-alvo específicos, e consolida-se o branding de lugares, havendo uma preocupação com a imagem que o lugar transmite e que ultrapassa as técnicas de publicidade (Kavaratzis \& Ashworth, 2008). Desta forma, o marketing das cidades poderá ser entendido como um elencar de atividades com o propósito de otimizar as funções urbanas, características e condições que favoreçam tanto a comunidade local como os seus visitantes, investidores e turistas, servindo de suporte ao desenvolvimento do local através da melhoria da sua capacidade concorrencial, funcionando, aliadas com um plano estratégico previamente traçado, como matriz de desenvolvimento sustentado (Azevedo et al., 2011; Torres, 2010). Segundo os mesmos autores, tais atividades têm como grande objetivo o reconhecimento e valorização dos bens e serviços que oferece aos seus públicos-alvo, o lograr um posicionamento de vantagem competitiva face a destinos concorrentes, o alcançar de benefícios positivos recorrentes de uma imagem positiva e, por último, o estabelecimento de relações de satisfação mútua, baseadas na superação de expectativas, que originem a fidelização.

\section{Branding territorial}

O branding de destinos tem, ao longo dos últimos anos, conhecido uma crescente popularidade entre as cidades e os seus gestores (Blain, Levy \& Ritchie, 2005; Hanzaee \& Saeedi, 2011), podendo ser descrito como o processo de criação e gestão de uma marca, 
através do uso das ferramentas de marketing. O processo é, em si mesmo, uma das ferramentas ao serviço dos gestores. Caldwell e Freire (2004) entendem que o branding é uma das mais poderosas ferramentas da estratégia de marketing, uma vez que na sua génese está sobretudo a criação e manutenção da reputação de um destino (Blair, Kung, Shieh \& Chen, 2014). Segundo Hudson e Ritchie (2009) os destinos "vendem-se" de forma similar, contudo no sentido de se conseguirem diferenciar, efetivamente, alguns têm vindo a optar por um posicionamento único através do branding da experiência no destino ao invés dos seus atributos. Por outras palavras, o branding de destinos de sucesso assenta na sua capacidade de reduzir a substituibilidade através da aposta na experiência do turista no local, apelando assim às suas emoções. $O$ processo de branding pode ser dividido em três etapas, a saber: a identidade da marca, o posicionamento da marca e a imagem da marca (Castillo-Villar, 2016). Para Cai (2002) e Hem e Iversen (2004), o branding de destinos consiste em selecionar um conjunto de elementos da marca para identificar e distinguir o local, através da construção de uma imagem positiva.

Na mesma linha, Keller (2013) argumenta que as cidades começam a despertar para a necessidade de se abordar a gestão das marcas cidade por via da sua imagem, por forma a aumentar as visitas, defendendo que o branding de países se tem tornado um fenómeno crescente, enquanto meio de apelo ao turista, sendo também uma opção para os destinos/cidades construírem uma imagem com associações de desejo (Azevedo, 2005). A aplicação do branding como forma de construção de uma imagem única e cativante, que servirá para identificar e diferenciar o destino, faz desta ferramenta de marketing uma "arma" determinante para o desenvolvimento e competitividade dos lugares (Paulo, 2013; Gaio \& Gouveia, 2007; Sousa \& Vasconcelos, 2018), já que para se ser competitive, para além de se atrair e satisfazer visitantes é necessário oferecer experiências únicas que se distingam das dos destinos concorrentes (Paulo, 2013).

O city branding é assim entendido como o meio quer para obter vantagens competitivas na atração e retenção de turistas e investimento (Kavaratzis, 2004; Huertas, 2010; Sousa \& Vasconcelos, 2018), quer para alcançar o desenvolvimento comunitário através do reforço da identidade local e da identificação dos residentes com a cidade (Kavaratzis, 2004). O branding territorial centra-se nas perceções e imagens de um destino (Moreira, 2010; Kavaratzis \& Ashworth, 2005), sendo o esforço cooperativo entre os diversos stakeholders um fator-chave para determinar o seu potencial ou fracasso no desenvolvimento de uma marca cidade (Winfield-Pfefferkorn, 2005; Pereira, 2009). Sem um sistema integrado de branding, nenhum local, seja um país ou uma cidade, poderá alcançar um desempenho ideal (Blair et al., 2014).

\subsection{Identidade}

Num mercado tão competitivo, as marcas, para se destacarem e diferenciarem das restantes, precisam de ter a sua própria identidade. Num destino turístico, a identidade da marca é formada pelas caraterísticas que os gestores do local pretendem transmitir, de forma a criar na mente do consumidor a imagem desejada. A identidade da marca deve concentrar-se em pontos de diferenciação que ofereçam sustentabilidade e vantagem competitiva relativa aos concorrentes (Ghodeswar, 2008).

Blair et al. (2014) defendem que a identidade de um país ou cidade começa desde logo pelo seu nome, cultura e pessoas, servindo esta para um país /cidade se diferenciar e 
comunicar com todos os seus públicos. Um lugar precisa ser diferenciado através de uma identidade de marca única se quiser ser, em primeiro lugar, reconhecido como existente, em segundo lugar, percebido na mente dos clientes do destino como possuidor de qualidades superiores aos dos concorrentes e, em terceiro lugar, consumido de forma proporcional aos objetivos definidos para o destino (Kavaratzis \& Ashworth, 2005). Gómez (2006) defende que a identidade urbana tem duas dimensões: a funcional e a cultural. A funcional diz respeito à razão de ser do território, estando traduzida no modelo de cidade e respetivas estratégias para cumprir os objetivos definidos, enquanto a cultural relaciona-se com os valores compartilhados pelos cidadãos acerca da sua cidade, o seu entorno e tudo aquilo que a pode influenciar.

A identidade de uma cidade e a sua imagem diferem (Pimentel, Pinho \& Vieira, 2006; Tinto Arandes, 2008; Azevedo et al., 2011). A identidade corresponde aos produtos ou serviços com os quais a marca quer ser percebida; por sua vez a imagem é o modo como esta se demonstra aos outros, como é percecionada (Hankinson, 2004; Pimentel et al., 2006; Tinto Arandes, 2008; Blair et al., 2014). Azevedo et al. (2011) definem a identidade como um mix, isto é, aquilo que a cidade parece ser, aquilo que realmente é, e principalmente, aquilo que pretende ser.

Em certos casos, os países - mesmo antes de um processo de branding - já têm alguma aparência de identidade, já que cada um traz consigo associações quer positivas quer negativas. Por vezes, o estereótipo de um país pode ficar aquém da realidade, havendo assim uma grande margem para a construção e definição do seu branding (Gilmore, 2002). A identidade territorial é o elemento vital sobre o qual uma cidade ou região erige a sua imagem (Azevedo et al., 2011), e pretende assim, medir, administrar e desenvolver uma imagem distinta do local com o objetivo de satisfazer os seus interesses através da criação de uma reputação internacional positiva (Blair et al., 2014).

\subsection{Marca destino}

Para Trueman, Klemm e Giroud (2004), as cidades podem ser vistas como marcas altamente complexas, em constante mudança, menos bem definidas e de difícil controlo quando comparadas com marcas corporativas. Segundo estes autores, as marcas devem ser honestas para que a identidade comunicada corresponda à identidade real. Huertas (2010) apresenta uma visão ligeiramente diferente da de Trueman et al. (2004) já que para esta investigadora os territórios, pese embora se devam basear nos seus atributos reais, não se devem centrar exclusivamente na sua identidade cultural, histórica e política mas também em caraterísticas criadas e fomentadas na cidade mesmo que estas não sejam originais, tradicionais. As marcas de cidades devem ser concebidas de forma global, ou seja, não deverá ser criada apenas para o público externo/turistas, mas também para os seus residentes, investidores, empresários, entre outros, de forma a não se perder a oportunidade de desenvolver o território.

As marcas de destinos poderão ser caracterizadas como tendo duas dimensões: a representacional, baseada nos atributos ligados à autoexpressão dos indivíduos, e a funcional, mais relacionada com os aspetos utilitários do destino. Os destinos quando vistos e trabalhados como marcas podem assim satisfazer necessidades básicas e de autorrealização (Caldwell \& Freire, 2004). Quando abordamos a marca de uma dada cidade, os seus residentes, para além dos segmentos de mercado a atingir, deverão ser vistos enquanto um segmento 
importante já que são um elemento-chave das estratégias das marcas cidade a ser desenvolvidas (Cardoso \& Diniz, 2012; Castillo-Villar, 2016).

De acordo com Lascu e Amesquita (2011), as marcas de destino devem envolver o públicoalvo, criar uma identidade forte e diferenciarem-se de outras ofertas semelhantes. A marca cidade, à semelhança da marca país, deve estar bem enraizada na realidade e em verdades fundamentais sobre o destino e deve conectar as pessoas, isto é, a marca país deve ser usada como a âncora sobre a qual se constrói a lealdade das pessoas, já que esta não pode ser tida como adquirida. A lealdade reveste-se tambem de igual importância no que diz respeito à realização da marca do país, ou seja, quer queiramos quer não, os seus residentes tornam-se a personificação da marca e os seus comportamentos e ações terão impacto na marca do país (Gilmore, 2002). A elaboração de uma marca de cidade deve estar sustentada nas características essenciais do território associadas aos atrativos e carateristícas que o públicoalvo valoriza (Huertas, 2010).

Sintetizando, a marca cidade é o próprio nome da cidade, (Pike, 2005; Gómez, 2006; Azevedo et al., 2011), símbolo, desenho ou a combinação destes que tem como objetivo diferenciar-se das concorrentes através da identificação, das características mais relevantes e seus atributos-chave aclopados a essa marca. A marca funciona como um meio de dar a conhecer um conceito, a imagem de uma cidade, o seu modelo urbano, sendo necessário, para que esta tenha sucesso, que crie sentimentos, desperte emoções convincentes e distintivas com o público (Azevedo et al., 2011), assumindo assim a marca do destino o papel de, através da imagem, criar uma identidade única que o diferencie dos outros (Greaves \& Skinner, 2010).

\subsection{Imagem}

O impacto turístico nos destinos está associado à sua imagem, havendo cada vez mais a necessidade de estes se renovarem, criarem novos polos de interesse e valorizarem o seu património (Ferreira, Aguiar \& Pinto, 2012), uma vez que a sua sobrevivência, num mercado cada vez mais competitivo, está largamente dependente da criação de uma imagem diferenciadora (Hanzaee \& Saeedi, 2011).

Pese embora a falta de uma definição consensual do conceito "imagem do destino" assim como um instrumento de medida da mesma, esta é tida como uma importante ferramenta do marketing turístico (Bigné, Sánchez \& Sánchez, 2001; Pimentel et al., 2006; Tsiotsou \& Ratten, 2010; Sharif \& Alimoradi, 2011), uma vez que pode ajudar as organizações a realizar os seus objetivos e desempenha sempre um papel decisivo na hora de decisão de compra por parte do consumidor afetado pela imagem (Tinto Arandes, 2008).

Tinto Arandes (2008), relativamente à imagem de uma cidade, afirma que esta é o conjunto de impressões e opiniões que os indivíduos formam acerca de um lugar, através do processamento das informações obtidas ao longo do tempo em diferentes fontes (Pereira, Anjos \& Añaña, 2014). É defendido por Tinto Arandes (2008) que a imagem de uma cidade deverá ser construída através da elaboração de planos de identidade e que esta deverá ser congruente e fiel com as suas características, quer históricas quer atuais. Tal requer investimento e planos estratégicos de largo alcance que envolvam o sector público e privado por forma a fortalezar a identidade do lugar e se garanta, assim, uma imagem duradoura e consistente no tempo. Existe ainda aquilo que podemos chamar de imagem percecionada, ou seja, aquilo que pensamos e temos como imagem de determinado local sem sequer o termos 
visitado, a imagem que criamos daquilo que nos dizem ou vemos em anúncios publicitários, brochuras, imagens na Internet, entre outros. Há inúmeros fatores que permitem idealizar e construir a imagem de um destino sejam eles pessoais, intrínsecos à pessoa, ou externos.

Tinto Arandes (2008) defende que a formação dessa perceção pode ser influenciada por feitos e factos históricos (geográficos, políticos, turísticos, entre outros), pelos pré-juízos ou ideias prévias que tenha o próprio indivíduo e até, segundo Azevedo et al. (2011), por meras ações banais do quotidiano. Blair et al. (2014) afirmam que a imagem de um local pode ser definida como as perceções dos indivíduos, dentro e fora de um país, podendo estas ser influenciadas pelos estereótipos, cobertura dos meios de comunicação social ou pela experiência pessoal.

Contudo, a má perceção de uma cidade pode ter impactos na sua imagem e daí advirem consequências para a sua prosperidade futura, uma vez que podem reduzir as probabilidades de investimento, prejudicar as atividades da comunidade empresarial local e ter um efeito sobre o número de visitantes, originando o seu declínio urbano. Em contraponto, uma perceção melhorada da marca, reforçada por evidências visuais de melhoria da cidade, pode reverter um eventual declínio urbano e criar as bases para um crescimento urbano (Trueman et al., 2004). Concluindo, para que a imagem de uma cidade assuma um papel estratégico, deverá estar alinhada com a consolidação da identidade local que responda a um sentimento de pertença sustentado nos padrões sociais, ambientais, culturais, geográficos, entre outros, uma vez que a imagem de uma cidade define um conjunto de atributos de caráter permanente inerentes à sua essência e que servem para que esta se diferencie de outras cidades concorrentes. A imagem de uma cidade é, no fundo, uma síntese da sua identidade (Azevedo et al., 2011).

\subsection{Imagem da marca}

A utilização da imagem de marca como meio de diferenciação é tão mais relevante quanto maior o ambiente competitivo (Rocha, Katayama, Fuhrer, \& Cherubini, 2013). O desenvolvimento de uma imagem de marca positiva é, atualmente, visto como um requisito de uma intervenção proactiva de marketing (Hankinson, 2007), sendo que, com o intuito de permanecerem competitivos, os destinos têm-na usado como estratégia que lhes permite dar a conhecer a sua imagem (Pimentel et al, 2006). A gestão da imagem de marca de uma cidade, robusta, organizada e voluntariamente aceite pelos residentes, exige um esforço conjunto de todos os envolvidos - entidades públicas, cidadãos, instituições e empresas privadas - uma vez que a imagem de uma cidade implica uma série de consequências económicas e comerciais (Tinto Arandes, 2008). Torna-se assim fulcral a consulta da comunidade local aquando da idealização da imagem de marca de um destino, já que para que esta tenha sucesso é necessário que seja aceite primeiramente pelos locais. A não auscultação da população residente originaria a que a imagem projetada não fosse aceite por estes, tornando difícil a sua consolidação e consequentemente a imagem projetada não corresponderia à real (Cruz \& Camargo, 2006). A construção de uma imagem de marca cidade sólida e congruente com a sua identidade constitui-se um desafio e ao mesmo tempo uma necessidade para os responsáveis locais, uma vez que tal permitirá descobrir, potenciar e comunicar os elementos diferenciadores que são importantes para os distintos segmentos, sejam eles nacionais ou internacionais (Tinto Arandes, 2008), tornando-se essencial para assegurar um 
posicionamento forte num mercado cada vez mais competitivo (Naidoo \& RamseookMunhurrun, 2012).

Os valores associados à imagem de marca turística, num contexto de concorrência entre destinos, será o elemento diferenciador, de valor acrescentado do destino, já que representam as primeiras sensações e emoções que o turista perceciona ainda antes de optar por um ou outro local (Morales \& Vela, 2009). As ideias dos dois parágrafos anteriores são resumidas por Azevedo et al. (2011) referindo que a criação, manutenção e otimização de uma imagem de marca da cidade estão estritamente ligadas à capacidade dos seus promotores conseguirem criar uma perceção nos consumidores o mais idêntica possível do idealizado e que se impôs como objetivo. Podemos assim concluir que se traduz na capacidade de impor/expor a identidade do local, que a imagem percecionada pelos consumidores vá ao encontro da imagem idealizada para a cidade, uma vez que, como defende Gómez (2006), a imagem de marca é o que nos vai definir como cidade.

\section{Eventos culturais}

Os eventos podem ser considerados uma estratégia de marketing com vista à promoção do território e competitividade entre cidades (Umbelino, 2016).

Como tal, tem aumentado nos últimos anos a concorrência entre cidades para atrair grandes eventos com capacidade para criar impacto, uma vez que estes têm a capacidade de atrair visitantes e de servir como estratégia de marketing para dar a conhecer uma nova imagem do local aos turistas, residentes e investidores (Barrera-Fernández, HernándezEscampa \& Vázquez, 2017).

Silva (2012) defende que os eventos são um instrumento-chave para a promoção de um território já que que fazem parte da estratégia de comunicação do mesmo, e quando associados aos atributos diferenciadores de um destino turístico, contribuem para dar a conhecer e reforçar a identidade de uma cidade enquanto local desejado para se viver, trabalhar e visitar.

Outo papel atribuído aos eventos é o de catalisador na vontade de repetição de visita ao lugar, uma vez que captam a atenção, contribuindo assim para o uso das atrações e equipamentos fixos existentes. Assumem-se como uma forma de rentabilizar os meios existentes, captando benefícios financeiros e ajudam na preservação e difusão do património artístico e cultural (Ribeiro et al., 2005). Os eventos assumem-se como um "parceiro" dos destinos turísticos, uma vez que contribuem para a construção ou renovação da sua imagem (Kotler \& Gertner, 2002), e como uma alternativa de promoção do destino, funcionando como construtores de imagens territoriais vividas no local (Morales \& Vela, 2009).

Os eventos culturais, como é o caso de estudo, são normalmente performativos, podendo ser realizados quer ao ar livre quer em infraestruturas criadas para o efeito, destacando-se a sua importância na realização em espaços considerados pela Unesco Património Mundial da Humanidade (Vieira, 2015). A crescente vaga de eventos culturais teve origem, por um lado no crescimento da procura de atividades culturais por parte das populações/turistas e, por outro, na necessidade de os destinos diversificarem a sua oferta turística por forma a captar novos segmentos de mercado (Umbelino, 2016).

A identidade de um lugar poderá ser desenvolvida ou mantida através da realização de eventos culturais (Marujo, 2014), uma vez que estes são, em muitos casos, o meio de um 
destino dar a conhecer as suas características únicas e a sua história. Para Umbelino (2016), a história e cultura perduram na imagem de um local, bem como na memória coletiva e orgulho das populações locais.

Os eventos geram o envolvimento de vários stakeholders, e no caso concreto dos eventos culturais, para que estes tenham sucesso, é necessário que sejam autênticos, que consigam um grande envolvimento e suporte da comunidade local e que os residentes se sintam identificados com o acontecimento (Disegna, Brida \& Osti, 2011). O turismo e os eventos têm sido amplamente utilizados em iniciativas que visam a regeneração urbana, através de estratégias promocionais enquadradas no marketing das cidades. O contributo dado por ambos deve estar enquadrado com as ações da política urbana dos destinos, com o foco na satisfação das necessidades dos potenciais mercados-alvo, na aplicação e promoção da identidade e imagem cultural, na melhoria da qualidade de vida dos cidadãos e na construção de uma vantagem competitiva para a cidade que lhe permita atrair habitantes, turistas e investidores (Deffner \& Metaxas, 2008).

Na mesma linha, Richards (2015) refere que, apesar de as cidades terem sempre recorrido aos eventos como forma de ajustar o ritmo vivido atualmente, os eventos têm um papel mais abrangente funcionando como meio de impulsionar a economia local, estimular a inclusão social, promover a cultura local, contribuir para a regeneração urbana e colocar as cidades nos mapas. Este autor defende que o valor dos eventos se sobrepõe ao das estruturas uma vez que, numa sociedade cada vez mais consumista, a novidade se sobrepõe à durabilidade levando até a que edifícios considerados icónicos necessitem dos eventos para renovarem a sua atratividade, ou seja, os próprios edifícios se tornam eventos e os eventos transformamse nos novos blocos de construção da cidade intangível.

Os eventos tornam- se importantes para o turismo pois podem ser um fator de deslocação de pessoas, mesmo que de curta duração, de diferentes lugares, e embora não criem destinos turísticos ajudam a criar e a manter a imagem dos destinos (Cunha \& Abrantes, 2013). Em termos de gestão estratégica, podem desempenhar um papel proeminente na criação da marca, posicionamento e promoção de um destino (Guerreiro, 2008; Dimanche, 2002: 77 citado por Marujo, 2014). A sua realização, quer para as entidades governamentais quer para as empresas, é tida como benéfica já que para além de serem uma forma de melhorar a imagem dos destinos turísticos também podem gerar benefícios para os locais, nomeadamente económicos, culturais, sociais e são uma arma contra a sazonalidade (Dimanche, 2008; Marujo, 2015), principalmente quando a sua realização ocorre em épocas denominadas baixas (Ribeiro et al., 2005). O principal benefício que os destinos poderão retirar dos eventos é a exposição da sua marca e desenvolvimento da sua imagem (Dimanche, 2008). Os eventos são uma forma de se criar uma imagem positiva dos destinos turísticos, promovendo a sua imagem como destino a ser visitado (Marujo, 2015). A cultura do local, recursos endógenos do destino turístico, recursos intangíveis e o papel da comunidade local têm contribuído de forma consensual e crescente para a construção de uma imagem diferenciadora dos destinos.

A este propósito, os eventos culturais assumem-se como ferramentas estratégicas na gestão dos territórios, contribuindo para a construção da oferta turística dos destinos e consequentemente para o desenvolvimento cultural, social e económico melhorando a imagem turística dos territórios (Santos et al., 2012; Sousa \& Ribeiro, 2018). No mesmo sentido, 
Ribeiro et al. (2005) afirmam que a celebração destes proporciona a criação de uma imagem do destino podendo ter efeitos positivos na imagem externa e interna de um território, revelando-se, quer do ponto de vista da oferta quer da procura, um produto turístico dinamizador dos destinos. Para Dimanche (2008) o que torna os eventos uma estratégia-chave para os destinos obterem uma vantagem competitiva em relação aos seus concorrentes é a sua poderosa dupla ação, ou seja, funcionam como criadores de imagem para o destino e como criadores de experiências para os visitantes.

\section{Contextualização e metodologia do caso de estudo: "Braga Romana"}

Braga tem nos últimos anos determinado, ou reforçado a sua aposta, em alguns eventos que permitam dar visibilidade ao destino e por conseguinte atrair turistas. Conforme descrito no sítio do Evento "Braga Romana", este tem como finalidade recriar a época em que a cidade fazia parte do Império Romano, denominada então de Bracara Augusta, fundada há mais de dois mil anos por César Augusto, imperador romano do séc. II a.C. Assim, através desta recriação é possível dar a conhecer todo o valioso património romano que a cidade possui, fazendo parte da estratégia de recuperação da história e património de Bracara Augusta. 10 evento decorre anualmente na cidade de Braga, normalmente entre maio e junho, desde o ano 2003. Nesse sentido, para o presente estudo optou-se por uma abordagem que combina as duas perspetivas: a qualitativa através da administração de entrevistas e a quantitativa através da aplicação de um inquérito por questionário in loco. As variáveis e as suas relações de causalidade estão patentes no modelo conceptual construído (Figura 1), tendo por base o modelo de Bigné et al. (2001), uma vez que com as suas seis variáveis foram construídas sete hipóteses passíveis de ser testadas através da recolha de dados.

A entrevista foi uma das técnicas utilizadas para a obtenção e compreensão dos dados desta investigação. De forma a conseguir-se o conhecimento e compreensão do papel do evento Braga Romana na definição da imagem de marca da cidade de Braga, optou-se pela técnica da entrevista semidirigida (ou semiestruturada, não diretiva controlada) e em profundidade com determinadas características especiais. Este tipo de entrevista é o mais produtivo para a recolha do tipo de dados e informação pretendidos para a presente investigação. Gauthier (2003) definiu alguns objetivos da entrevista semidirigida: tornar explícitos os contextos e realidades das pessoas participantes no estudo; a compreensão do seu mundo; ajudar a apreender, organizar e a estruturar o pensamento do interlocutor; permitir um aprofundamento, uma reflexão, uma tomada de consciência e transformação das pessoas envolvidas (tanto do investigador, como do respondente).

Por conseguinte, importa reforçar que nas entrevistas semidirigidas existe um postulado de que a perspetiva do outro é aquela que tem sentido, existindo assim o objetivo de a conhecer, torná-la explícita e compreensível. Foram assim efetuadas duas entrevistas a especialistas, previamente à realização do evento. Complementarmente, foi tomada a decisão de testar empiricamente o modelo concetual baseado no contributo de Bigné et al. (2001), tendo como principal objetivo perceber qual o papel dos eventos

\footnotetext{
${ }^{1}$ http://bragaromana.cm-braga.pt/
} 
culturais na construção da marca, imagem e qualidade percebida acerca de um destino, aplicado ao caso concreto do evento "Braga Romana" na cidade de Braga. Foi levada a cabo uma investigação de natureza qualitativa e quantitativa por forma a compreender qual a visão dos responsáveis pelas áreas objeto de estudo, turismo e eventos, e a perceção dos visitantes do evento.

Os resultados indicam que os eventos culturais, e concretamente no caso de estudo o evento "Braga Romana" no destino Braga, desempenham um papel determinante no território. Funcionam como uma ferramenta que permite dar a conhecer o território, captam visitantes e ajudam a difundir a imagem de marca do destino (Figura 1).

Figura 1. Modelo conceptual proposto

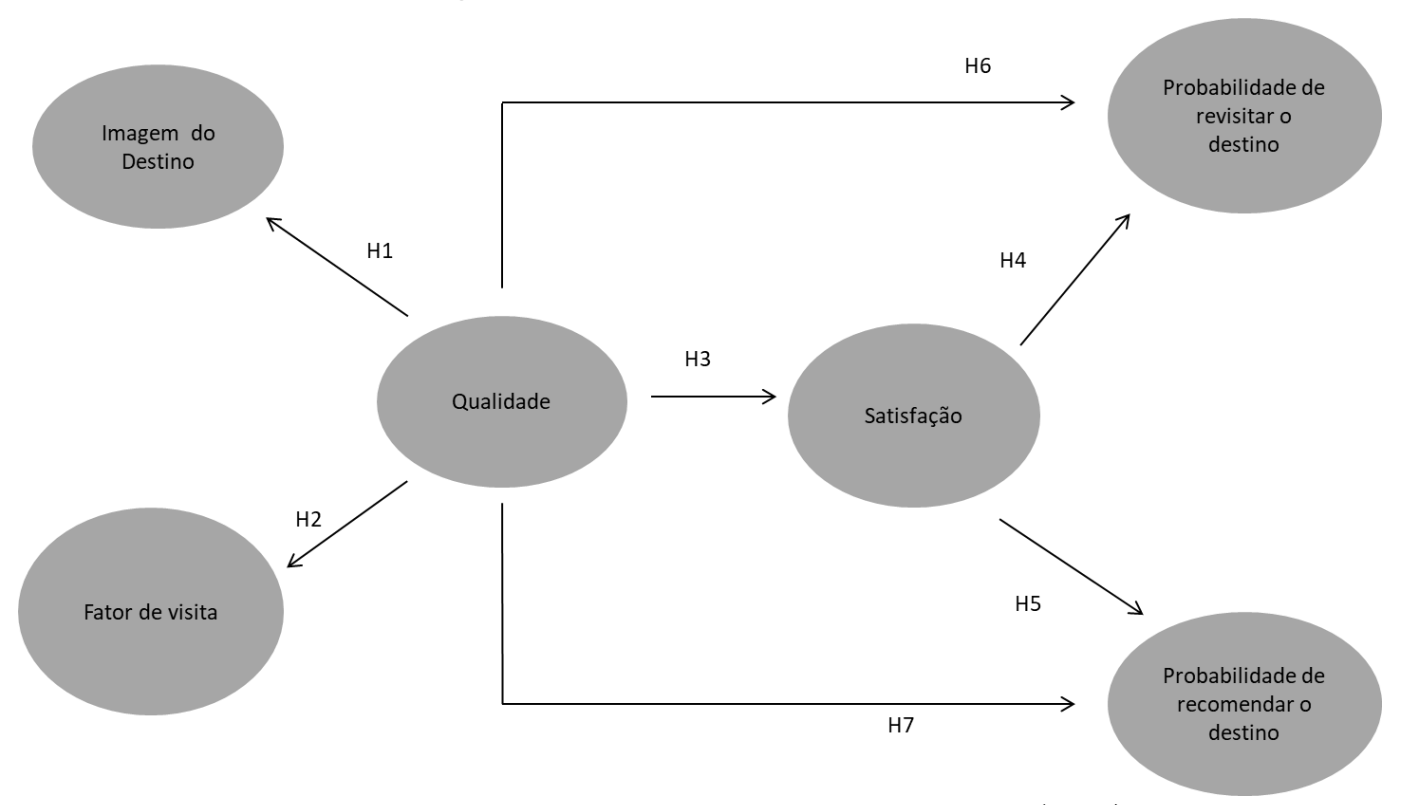

Fonte: Elaboração própria com base em Bigné et al. (2001).

As questões apresentadas no questionário são estruturadas sob a forma de questões fechadas e semiabertas. As questões fechadas propõem um leque de respostas previamente fixado cabendo ao inquirido assinalar uma ou várias das opções, consoante se trate de respostas simples ou múltiplas. Quando bem elaboradas, as questões fechadas são fáceis de compreender, preencher, tratar, interpretar e quantificar, não necessitando de análise de conteúdo. No entanto, "são maiores os riscos de artificialismo, enviesamento e influência das respostas, de redução dos matizes e de exposição a respostas de fachada" (Gonçalves, 2004:84). As respostas previstas devem ser de fácil compreensão e nenhuma resposta deve merecer especial destaque, sendo todas da mesma dimensão, nível e âmbito.

As hipóteses postuladas encontram-se previstas na literatura, tendo por base os argumentos propostos e contributos evidenciados no enquadramento teórico, em específico, no sentido de que a satisfação tende a favorecer o desenvolvimento de comportamentos de lealdade. Estes resultados são particularmente evidenciados em contextos de turismo, como disso sejam exemplo a importância da satisfação na revisita ou na recomendação a familiares e/ou amigos (Kozak, 2003; Bigné et al., 2001; Prayag, 2008; Prayag \& Ryan, 2012). Com base nessa discussão, propomos que, num contexto de 
turismo religioso e de peregrinação, o aumento da satisfação facilite o desenvolvimento de comportamentos de lealdade.

Nas questões semiabertas, as principais respostas são previstas tal como numa questão fechada. Mas, para além destas, os inquiridos podem optar por respostas livres. Existe uma limitação, pois observa-se uma tendência dos inquiridos, "por comodismo, conformismo ou outros motivos, para se limitarem à parte fechada da questão" (Gonçalves, 2004:84). O sucesso desta técnica explica-se por esta ser uma técnica aparentemente fácil e rápida de aplicar, ser padronizada e rotinizada. $O$ inquérito aplicado aos turistas/visitantes do evento Braga Romana encontra-se organizado em 3 blocos de questões garantindo a confidencialidade e o anonimato dos inquiridos.

O primeiro bloco de perguntas é constituído por questões que permitem aferir os motivos da visita, se viajam sozinhos ou acompanhados, se os visitantes conheciam previamente o destino e/ou como o conheceram e quais os atributos que estes valorizaram para optar pelo mesmo. De seguida, o segundo bloco aborda questões relacionadas com a imagem do destino e a sua correlação com o evento Braga Romana. $O$ terceiro e último bloco de perguntas é relativo à caracterização sociodemográfica do inquirido, nomeadamente género, idade, escolaridade, país e cidade de residência e nacionalidade. Os dados recolhidos pelo inquérito por questionário foram analisados em termos quantitativos (recurso ao SPSS versão 22 para Windows), específico para o tratamento de variáveis quantitativas. Neste sentido e para testar as hipóteses elaboradas, foram usados procedimentos estatísticos de acordo com as variáveis em análise.

\section{Análise e discussão de resultados}

Os resultados obtidos evidenciam que a cidade de Braga assumiu a decisão de criar uma marca destino estando neste momento a decorrer um trabalho conjunto entre a autarquia e a Associação Comercial de Braga que auscultou um conjunto variado de stakeholders por forma a ser feito um diagnóstico e assim se perceber aquilo que é realmente importante ou não para a cidade. O trabalho de branding do destino já tem vindo a ser feito, com a criação de um logo específico para o município, estando-se agora mais focado para apostar na vertente do turismo e no lançamento da marca a nível internacional. 0 trabalho realizado pela autarquia e seus parceiros permitirá redefinir a estratégia, não sendo ainda certo que o slogan e logotipo a usar para o efeito venham a ser os mesmo que atualmente. A cidade é "trabalhada" sobre o slogan geral "Braga Cidade Autêntica", mas posteriormente, associado a este, para cada um dos diferentes conjuntos de atividades desenvolvidas é criado um logotipo e respetivo slogan. A identidade de um destino turístico assume-se como um fator de diferenciação em relação aos seus concorrentes e, nesse sentido, a identidade da cidade de Braga, neste momento, assenta sobretudo no seu património, mas tem nos últimos tempos procurado redefinir-se por forma a atrair novos segmentos de mercado. A imagem que se pretende transmitir do destino, a par da sua autenticidade, diversidade e beleza, é que este é acolhedor, ou seja, sabe receber. É importante tentar transmitir-se a imagem de um destino turístico, cultural e economicamente forte associada a conceitos como o empreendedorismo, inovação e desenvolvimento sustentável. Os eventos levados a cabo, e essencialmente o evento 
"Braga Romana", que é trabalhado o ano inteiro, são o veículo usado para transmitir a imagem que se pretende transparecer de Braga. Em suma, ambiciona-se que a imagem do evento seja um reflexo da imagem da cidade. A realização de eventos acaba por ser a responsável pelos fluxos turísticos da cidade, uma vez que são uma ferramenta na construção de uma cidade ativa e dinâmica. Portanto a sua realização torna-se benéfica na promoção do território, servindo como montra daquilo que é a cidade, a sua cultura endógena, e no caso concreto do evento em estudo serve de catalisador da visita, dando hipótese de se conhecer todo o património romano existente e despertando quem visita o destino para a descoberta de tudo mais que tem a oferecer. Ou seja, promovem o destino, atraem visitantes e incentivam o seu retorno. Os eventos culturais assumem-se também como criadores da imagem de marca de um destino turístico, assumindo Braga esse caminho. Pese embora o nome "Braga" sobressaia mais que qualquer evento, a realização da "Braga Romana" permite mostrar essa imagem de marca, de Braga associada à história, ao património e cultura.

No mesmo sentido, a recolha de dados cingiu-se a um único contexto, o evento Braga Romana, onde foram implementados 104 questionários no decorrer do mesmo. A amostra de estudo é constituída por turistas/visitantes presentes no evento "Braga Romana" na cidade de Braga, sendo composta por um total de 104 inquiridos. Quanto ao género, tratase de uma amostra homogénea uma vez que é composta por $45(43,3 \%)$ indivíduos do sexo masculino e $59(56,7 \%)$ do sexo feminino. No que concerne à idade dos turistas inquiridos, a análise dos dados permitiu-nos verificar que mais de metade $(54,8 \%)$ da amostra se encontra na faixa etária dos 18 aos 34 anos, em suma estamos perante uma amostragem sobretudo jovem, adulta. As duas faixas etárias com maior número de respondentes foram então a de 18-24 anos com 33 pessoas (31,7\%) e a de $25-34$ anos com 24 pessoas (23,1\%). Os restantes escalões etários obtiveram número similar de inquiridos entre eles. O escalão etário 35-44 anos inclui 14 inquiridos (14,4\%), o compreendido entre 45-54 é composto por 11 inquiridos (10,6\%), o de 55-64 por 12 (11,5\%) e por último o escalão que engloba os inquiridos com 65 ou mais anos é composto por 9 pessoas $(8,7 \%)$.

No que diz respeito à nacionalidade, embora exista alguma variedade, a maioria dos inquiridos são portugueses $(58,7 \%)$, sendo que mais de $71,2 \%$ da amostra diz respeito a indivíduos de nacionalidade portuguesa e espanhola. Assim, a distribuição é a seguinte: 61 indivíduos $(58,7 \%)$ de nacionalidade portuguesa, 13 (12,5\%) de nacionalidade espanhola, $11(10,6 \%)$ de nacionalidade francesa, $8(7,7 \%)$ de nacionalidade brasileira, $6(5,8 \%)$ de nacionalidade alemã, $2(1,9 \%)$ de nacionalidade inglesa, 1 (1,0\%) de nacionalidade húngara, $1(1,0 \%)$ de nacionalidade cabo verdiana e $1(1,0 \%)$ de nacionalidade macaense. Estes resultados demonstram que, embora aquando da recolha de dados já estivéssemos numa época considerada alta para o turismo, os turistas/visitantes da cidade naquele momento e espaço eram sobretudo nacionais e do país fronteiriço Espanha. No que concerne às habilitações literárias, a amostra possui, predominantemente, uma licenciatura, com um número total de 41 respostas $(39,4 \%)$ em 104 . Relativamente às restantes habilitações, 0 ensino secundário obteve 24 respostas (23,1\%), o mestrado 15 (14,4\%), o ensino básico 14 (13,5\%), e o doutoramento 10 respondentes (9,6\%).

De seguida irá ser apresentada uma matriz, elaborada no SPSS, com a correlação existente entre as diferentes variáveis utilizadas no modelo concetual anteriormente 
proposta. Tal pretende verificar a relação existente entre variáveis e consequentemente se as hipóteses pré-elaboradas para este estudo se verificam/confirmam. Usou-se assim o coeficiente de correlação de Pearson que mais não é do que um coeficiente que permite verificar em que sentido e grau duas variáveis se correlacionam e associam linearmente (Figueiredo, 2009; Graça Martins, 2014). O referido coeficiente varia entre -1 e 1 e quanto maior for o seu valor maior será a associação entre as variáveis. Quanto ao sinal negativo ou não, significa que se o valor for negativo a associação entre as variáveis é negativa, ou seja, se os valores de uma variável sobem normalmente os valores da outra diminuem e por sua vez se a correlação for positiva, em caso de coeficiente positivo, significa que existe uma associação linear entre as variáveis, se uma aumenta a outra também. Importa referir que se o valor for o não existe relação linear entre variáveis e que quanto mais próximo de 1 for o valor, independentemente do sinal, maior é a relação de dependência entre variáveis (Figueiredo, 2009; Graça Martins, 2014).

Tabela 2. Matriz das correlações das variáveis integrantes do modelo conceptual proposto

\begin{tabular}{|c|c|c|c|c|c|c|c|c|c|c|}
\hline Variáveis & $\begin{array}{l}\stackrel{\mathscr{L}}{\Phi} \\
\pm\end{array}$ & $\mathbf{z}$ & 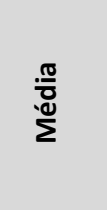 & 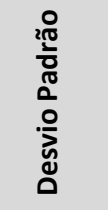 & 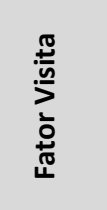 & 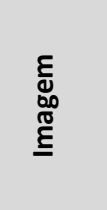 & $\begin{array}{l}\frac{\pi}{0} \\
\frac{\pi}{\pi} \\
\frac{\pi}{\pi} \\
\frac{\pi}{2} \\
0\end{array}$ & 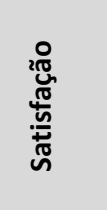 & 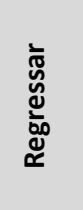 & 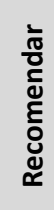 \\
\hline Fator Visita & 10 & 104 & 3,6808 & ,51333 & & & & & & \\
\hline Imagem & 3 & 104 & 3,7212 & 66034, & -,159 & & & & & \\
\hline Qualidade & 2 & 104 & 4,1971 & 66251 & ,203* & ,245* & & & & \\
\hline Satisfação & 2 & 104 & 4,4087 & ,62226 & 128 & 130 &, $592 * *$ & & & \\
\hline Regressar & 1 & 104 & 4,2404 & 67544 &, $324 * *$ &,- 008 & ,208* &, $272 * *$ & & \\
\hline Recomendar & 2 & 104 & 4,6779 & 46173 &,- 051 & ,334** & ,590** &, $522 * *$ & ,220* & \\
\hline
\end{tabular}

* A correlação é significativa no nível de 0,05 (2 extremidades)

** A correlação é significativa no nível de 0,01 (2 extremidades)

Fonte: Elaboração própria com recurso a dados obtidos através do SPSS.

Seguidamente, iremos proceder ao teste das hipóteses previamente definidas.

H1: A imagem do destino é influenciada pela qualidade percecionada do evento.

A hipótese 1 foi testada recorrendo às variáveis imagem e qualidade. De acordo com a correlação existente entre as variáveis, $0,245^{*}$ significativa no nível 0,05 constatamos que a hipótese se confirma. Poderemos então deduzir que os eventos culturais e a sua qualidade, enquanto parte integrante da oferta de um destino turístico, e neste caso concreto o evento Braga Romana, têm influência na imagem criada da cidade de Braga. Esta hipótese vem, assim, confirmar aquilo que está patente na revisão de literatura, os eventos funcionam, também, como ferramenta na construção, definição e moldagem de uma marca destino.

H2: O fator de visita é influenciado pela qualidade percecionada do evento. 
A hipótese 2 verificou-se através da utilização das variáveis fator de visita e qualidade. De acordo com a correlação existente entre as variáveis, 0,203* com significância ao nível de 0,05, a hipótese é confirmada. Verificamos que a decisão de visitar o destino está significativamente relacionada com a qualidade percecionada do evento.

H3: A qualidade percebida tem um efeito positivo na satisfação.

A hipótese 3 foi testada recorrendo às variáveis qualidade e satisfação. De acordo com a correlação existente entre as variáveis, 0,592** significativa no nível 0,01, constatamos que a hipótese se confirma com uma correlação moderada. De acordo com estes resultados percebemos que a qualidade percecionada pelos visitantes/turistas com a experiência tem influência na satisfação obtida; quanto maior a qualidade percecionada maior será a satisfação obtida.

H4: A satisfação com o evento tem influência na probabilidade de revisitar o destino.

A hipótese 4 verificou-se através da utilização das variáveis satisfação e regressar. De acordo com a correlação existente entre as variáveis, 0,272** significativa ao nível de 0,01, poderemos confirmar a hipótese concebida. Aquilo que se deduz dos resultados obtidos é que a satisfação obtida com o evento influencia significativamente a probabilidade de se revisitar o destino.

H5: A satisfação com o evento tem influência na probabilidade de recomendar o destino.

A hipótese 5 foi testada recorrendo às variáveis satisfação e recomendar. De acordo com a correlação existente entre as variáveis, 0,522** significativa no nível 0,01, constatamos que a hipótese se confirma com uma correlação moderada. Os resultados demonstram que a satisfação obtida com a experiência influencia positivamente a probabilidade de se recomendar o destino.

H6: A qualidade percebida do evento tem um efeito positivo na probabilidade de revisitar o destino.

A hipótese 6 verificou-se através da utilização das variáveis qualidade e regressar. De acordo com a correlação existente entre as variáveis, 0,208* significativa ao nível de 0,05, poderemos confirmar a hipótese. Depreende-se que a qualidade percecionada do evento tem influência significativa na probabilidade de revisitar o destino.

H7: A qualidade percebida do evento tem um efeito positivo na probabilidade de recomendar o destino.

Para se proceder ao teste da hipótese 7 utilizaram-se as variáveis qualidade e recomendar. De acordo com a correlação moderada existente entre as variáveis, 0,590** com significância ao nível de 0,01, a hipótese é confirmada. De acordo com estes resultados existe uma relação positiva entre a qualidade percecionada e a probabilidade recomendar o destino. Em suma, constatamos que das sete hipóteses propostas inicialmente nenhuma foi negada com os dados obtidos. Verifica-se que o nível de 
significância é mais elevado nas variáveis recomendar, qualidade, satisfação e regressar do que nas variáveis imagem e fator de visita.

\section{Conclusões, limitações e recomendações}

Em resultado do presente estudo, compreende-se que os responsáveis pelo destino Braga estão conscientes da importância da gestão do mesmo enquanto marca, tendo vindo a desenvolver ao longo dos últimos anos um extenso trabalho de parceria e cooperação com os diferentes stakeholders por forma a atrair visitantes e promover o destino. Até ao presente, a cidade, de forma genérica, tem atuado com um logotipo e slogan universal na sua comunicação, estando neste momento em fase de redefinição da sua estratégia com o intuito de projetar a marca internacionalmente, mais centrada na vertente turística. Conclui-se assim, que os responsáveis do destino veem os eventos culturais, e concretamente o evento "Braga Romana", como geradores da imagem de marca de um destino e como meio de a dar a conhecer, isto é, o evento "Braga Romana" permite divulgar a imagem de marca da cidade: Braga associada à história, ao património e à cultura. Os eventos, de acordo com os resultados obtidos, podem ser encarados como uma ferramenta estratégica na criação, desenvolvimento e divulgação da imagem de marca de um território por parte dos seus responsáveis. Têm assim uma dupla ação, funcionam como catalisador da visita e como meio de promover o destino. Constata-se que Braga beneficia com a criação dos eventos culturais e que o evento "Braga Romana" teve impacto em todas as variáveis de estudo. O evento funcionou como fator de visita do destino e teve impacto na imagem de marca do destino. Outras conclusões do estudo são: a qualidade percebida influenciou a satisfação dos visitantes e a satisfação com o evento teve impacto na probabilidade de recomendar e revisitar o destino.

Em suma, Braga e os seus responsáveis conseguiram através da realização do evento “Braga Romana” transmitir a sua identidade, tradição, costumes, história e património, ou seja, a sua imagem de marca. Portanto verifica-se que foi seguida uma estratégia correta, importando nesta fase monitorizar, com um instrumento fidedigno, o trabalho desenvolvido, por forma a verificar efetivamente a necessidade de se proceder ou não a um rebranding da marca. Uma das principais limitações deste estudo prende-se com o número reduzido da amostra. Este constrangimento resulta da implementação do inquérito in loco, embora fundamental, uma vez que a disposição dos visitantes para responder por vezes era nula e nas horas de mais afluência, em certas zonas do evento, era quase impossível a aplicação dos questionários.

Numa época em que a mudança é uma constante, muitos dos estudos existentes sobre os eventos centram-se sobretudo nos diferentes impactos criados com a sua realização, contudo estes já não são atualizados. Desta forma, o contributo desta investigação reside numa nova abordagem, analisando o papel que os eventos desempenham na imagem de marca de um destino turístico. Com o desenvolvimento desta investigação sugere-se a extensão deste tema para uma vertente mais socioeconómica, no sentido de verificar o papel dos eventos culturais no desenvolvimento económico e social nas cidades, alargando assim o estudo a um âmbito mais nacional não o limitando à esfera regional. Através dos resultados apresentados deverão ser desenvolvidas outras análises, como, por exemplo, as análises de regressão 
(ou seja, como determinadas variáveis influenciam outra variável, ou seja, verifica como o comportamento de uma(s) variável(is) pode mudar o comportamento de outra). Seria igualmente interessante a utilização deste modelo para medir o impacto criado pelos eventos no setor hoteleiro, ou seja, até que ponto são um meio de aumentar a ocupação e receita das unidades hoteleiras. Espera-se que futuros trabalhos possam contribuir para o desenvolvimento de estudos empíricos que testem as relações causais aqui abordadas. Um estudo empírico deverá possibilitar a maior compreensão dos construtos do modelo de investigação e consequente relação entre as variáveis de estudo. $O$ estudo das relações propostas permite medir o impacto de certos fatores na predisposição para o destino turístico em contextos culturais. Assim, um estudo empírico permitirá não apenas testar as hipóteses de investigação como também avaliar o seu efeito preditivo (por exemplo, através de modelo de equações estruturais). Para além disso, compreender o comportamento do consumidor em contextos específicos de turismo religioso e de peregrinação permitirá, entre outros aspetos, reunir e providenciar informação útil para o planeamento dos destinos turísticos, assim como para suporte da tomada de decisão dos demais agentes envolvidos.

\section{Referências}

Azevedo, A. (2005). Cities as brands: The role of communication strategy in place marketing context. In C. Camponez, G. Baptista Ferreira, J. Miranda, P. Jerónimo \& S. Meireles Graça (Eds.) Repensar os media: Novos contextos da comunicação e da informação, $4 .^{\circ}$ SOPCOM: Associação Portuguesa de Ciências da Comunicação (pp. 1777-1786). Aveiro: Universidade de Aveiro.

Azevedo, A., Magalhães, D. \& Pereira, J. (2011). City marketing - MyPlace in XXI. Porto: Vida Economica Editorial.

Barrera-Fernández, D., Hernández-Escampa, V. A. \& Vásquez, A.B. (2017). Impacto de los festivales en el turismo patrimonial: El caso del Festival Internacional Cervantino. International Journal of Scientific Management and Tourism, 3(3), 47-66.

Bianchini, F. \& Ghilardi, L. (2007). Thinking culturally about place. Place Branding and Public Diplomacy, 3(4), 280-286.

Bigné, J. E., Sánchez, M. I. \& Sánchez, J. (2001). Tourism image, evaluation variables and after purchase behaviour: Inter-relationship. Tourism Management, 22(6), 607-616. doi: 10.1016/S02615177(01)00035-8

Blain, C., Levy, S. E. \& Ritchie, J. B. (2005). Destination branding: Insights and practices from destination management organizations. Journal of Travel Research, 43(4), 328-338. doi: $10.1177 / 0047287505274646$

Blair, T. C., Kung, S. F., Shieh, M. D., \& Chen, K. H. (2015). Competitive identity of a nation. Global Studies Journal, 8(1), 13-29.

Braga, C. M. (2017). Freguesias. Obtido de Web site da Câmara Municipal de Braga: https://www.cm-braga.pt/pt/0103/municipio/freguesias/apresentacao

Braga, M. d. (2017). Braga Romana. Obtido de O evento: http://bragaromana.cmbraga.pt/index.php/2016-01-26-18-49-21/braga-romana

Cai, L. A. (2002). Cooperative branding for rural destinations. Annals of Tourism Research, 29(3), 720-742. doi: 10.1016/S0160-7383(01)00080-9

Caldwell, N. \& Freire, J. R. (2004). The differences between branding a country, a region and a city: Applying the Brand Box Model. Journal of Brand Management, 12(1), 50-61.

Cardoso, P. R. \& Diniz, A. O. (2012). A marca cidade avaliada pelos seus residentes: As dimensões do seu valor e a sua influência na satisfação. Cadernos de Estudos Mediáticos, 15-28.

Castillo-Villar, F. R. (2016). Alcances y límites de la marca ciudad en la gestión de la imagen de la ciudad. Revista Venezolana de Gerencia, 21(73), 157-171.

Cunha, L. \& Abrantes, A. (2013). Introdução ao turismo (5. ${ }^{a}$ Ed.). Lisboa: Lidel. 
Cruz, G. D. \& Camargo, P. D. (2006). A construção da imagem de marca dos destinos turísticos através de seu patrimônio cultural intangível. Comunicação apresentada no IV SeminTUR-Seminário de Pesquisa em Turismo do MERCOSUL. Caxias do Sul, RS, 7.

De Carlo, M., Canali, S., Pritchard, A., \& Morgan, N. (2009). Moving Milan towards Expo 2015: Designing culture into a city brand. Journal of Place Management and Development, 2(1), 822. doi: $10.1108 / 17538330910942762$

Deffner, A. \& Metaxas, T. (2008). The cultural and tourist policy dimension in city marketing: The case of the olympic municipality of Nea Ionia, Magnesia, Greece. MPRA - Munich Personal RePEc Archieve, 321-342.

Dimanche, F. (2008). From attractions to experiential marketing: The contributions of events to "new" tourism. In C. Kronenberg, S. Mueller, M. Peters, M. Pikkemaat, \& K. Weiermair (Eds.), Change management in tourism (pp. 173-184). Berlin: Erich Schmidt Verlag.

Disegna, M., Brida, J. \& Osti, L. (2011). Authenticity perception of cultural events: A host-tourist analysis.

Ferreira, L., Aguiar, L. \& Pinto, J. R. (2012). Turismo cultural, itinerários turísticos e impactos nos destinos. CULTUR: Revista de Cultura e Turismo, 6(2), 109-126.

Fetscherin, M. (2010). The determinants and measurement of a country brand: The country brand strength index. International Marketing Review, 27(4), 466-479. doi: 10.1108/02651331011058617

Figueiredo, D. (2009). Desvendando os mistérios do coeficiente de correlação de Pearson (r). Revista Política Hoje, 18(1), 115-146. doi: 10.11606/issn.2237-4485.lev.2014.132346

Gaio, S. \& Gouveia, L. (2007). O branding territorial: Uma abordagem mercadológica à cidade. Revista A Obra Nasce, 4, 27-38.

García, Y. (2009). La ciudad como espectáculo. Marketing territorial, internet y atracción turística en Santiago de Compostela. ¿Éxito o fracaso? UOC Papers: Revista sobre la sociedad del conocimiento, (8), 1-10.

Gauthier, B. (2003). A estrutura da prova. In B. Gauthier (Ed.), Investigação Social: Da problemática à colheita de dados (pp. 143-174). Loures, Portugal: Lusociência.

Ghodeswar, B. M. (2008). Building brand identity in competitive markets: A conceptual model. Journal of Product \& Brand Management, 17(1), 4-12. doi: 10.1108/10610420810856468

Gilmore, F. (2002). A country - Can it be repositioned? Spain - The success story of country branding. Journal of Brand Management, 9(4), 281-293.

Gómez, M. (2006). El barrio de Lavapiés, laboratorio de interculturalidad. Dissidences. Hispanic Journal of Theory and Criticism, 1(2), 1-42.

Gonçalves, A. (2004). Métodos e técnicas de investigação social I. Programa, conteúdo e métodos de ensino teórico e pratico (Relatório apresentado à Universidade do Minho para provas de agregação no grupo disciplinar de sociologia). Braga: Universidade do Minho, Instituto de Ciências Sociais.

Graça Martins, E. (2014). Coeficiente de correlação amostral. Revista de Ciência Elementar, 2(2).

Greaves, N. \& Skinner, H. (2010). The importance of destination image analysis to UK rural tourism. Marketing Intelligence \& Planning, 28(4), 486-507. doi: 10.1108/02634501011053586

Guerreiro, M. (2008, April). O papel da cultura na gestão da marca das cidades. In VI Congresso Português de Sociologia, Mundos Sociais: Saberes e Práticas.

Hankinson, G. (2004). Relational network brands: Towards a conceptual model of place brands. Journal of Vacation Marketing, 10(2), 109-121. doi: 10.1177/135676670401000202

Hankinson, G. (2007). The management of destination brands: Five guiding principles based on recent developments in corporate branding theory. Journal of Brand Management, 14(3), 240-254.

Hanzaee, K. H. \& Saeedi, H. (2011). A model of destination branding for Isfahan city: Integrating the concepts of the branding and destination image. Interdisciplinary Journal of Research in Business, 1(4), 12-28.

Hem, L. E. \& Iversen, N. M. (2004). How to develop a destination brand logo: A qualitative and quantitative approach. Scandinavian Journal of Hospitality and Tourism,4(2), 83-106. doi: $10.1080 / 15022250410003852$

Hudson, S. \& Ritchie, J. B. (2009). Branding a memorable destination experience. The case of 'Brand Canada'. International Journal of Tourism Research, 11(2), 217-228. doi: 10.1002/jtr.720

Huertas, A. (2010). Las claves del citybranding. Portal de la Comunicación InCom-UAB-Leciones del portal. [Documento online].

Kavaratzis, M. (2004). From city marketing to city branding: Towards a theoretical framework for developing city brands. Place Branding, 1(1), 58-73. 
Kavaratzis, M. \& Ashworth, G. J. (2005). City branding: An effective assertion of identity or a transitory marketing trick? Tijdschrift Voor Economische en Sociale Geografie, 96(5), 506-514. doi: 10.1111/j.1467-9663.2005.00482.x.

Kavaratzis, M. \& Ashworth, G. (2008). Place marketing: How did we get here and where are we going? Journal of Place Management and Development, 1(2), 150-165. doi: 10.1108/17538330810889989

Keller, K. L. (2013). Strategic brand management. Building, measuring, and managing brand equity ( $4^{\text {th }}$ ed.). Boston: Pearson Education.

Kotler, P. \& Gertner, D. (2002). Country as brand, product, and beyond: A place marketing and brand management perspective. Journal of Brand Management, 9(4), 249-261.

Kozak, M. (2003). Measuring tourist satisfaction with multiple destination attributes. Tourism Analysis, 7(3-4), 229-240. doi: 10.3727/108354203108750076

Lascu, D.-N. \& Amesquita, E. R. (2011). Branding the controversial: Challenges in destination branding. Innovative Marketing, 7(2), 20-28.

Marujo, M. N. (2014). Turismo e eventos culturais: A festa da flor na llha da Madeira e as motivações dos turistas. Investigaciones Turísticas, 71-86. doi: 10.14198/INTURI2014.7.04

Marujo, N. (2015). O contributo do turismo de eventos para o desenvolvimento turístico de uma região. Revista DELOS - Desarollo Local Sostenible.

Moilanen, T. \& Rainisto, S. (2009). How to brand nations, cities and destinations. A planning book for place branding. UK: Palgrave MacMillan, 65-75.

Morales, M. J. \& Vela, J. d. (2009). Identidad territorial y promoción turística: La organización de eventos como estrategia de creación, consolidación y difusión de la imagen de marca del territorio. Zer, 14(26), 277-297.

Moreira, P. H. V. M. (2010). Gestão de marcas cidade. O caso da marca Porto Turismo (Dissertação de mestrado não publicada). Universidade do Porto, Portugal.

Naidoo, P. \& Ramseook-Munhurrun, P. (2012). The brand image of a small island destination: The case of Mauritius. Global Journal of Business Research, 6(1), 55-64.

Paulo, S. C. (2013). Branding de destinos turísticos de cidade: A imagem como determinante para consolidar o posicionamento de Lisboa (Tese de doutoramento não publicada). Escola Superior de Turismo e Tecnologia do Mar, Instituto Politécnico do Mar, Leiria, Portugal.

Pereira, R. (2009). Towards an understanding of epistemology of the brand concept and its use in tourism. Comunicação apresentada na III Congresso Internacional de Turismo de Leiria e Oeste, Leiria.

Pereira, M. D.L., Anjos, F. A. \& Añaña, E. da S. (2014). Avaliação da imagem de um destino turístico: O caso de Porto Belo (SC). In Anais do Seminário da Associação Nacional e Pós-Graduação em Turismo (pp.1-20). Fortaleza, Brasil: ANPTUR.

Pike, S. (2005). Tourism destination branding complexity. Journal of Product \& Brand Management, 14(4), 258-259. doi: 10.1108/10610420510609267

Pimentel, E., Pinho, T. \& Vieira, A. (2006). Imagem da marca de um destino turístico. Turismo, Visão e Ação, 8(2), 283-299. doi: 10.14210/rtva.v8n2.p283-299.

Prayag, G. (2008). Image, satisfaction and loyalty: The case of Cape Town. Anatolia: An International Journal of Tourism and Hospitality Research, 19(2), 205-24. doi:10.1080./13032917.2008.9687069

Prayag, G. \& Ryan, C. (2012). Antecedents of tourists' loyalty to Mauritius: The role and influence of destination image, place attachment, personal involvement and satisfaction. Journal of Travel Research, 51(3), 342-356. doi: 10.1177/0047287511410321

Ribeiro, J. C., Vareiro, L. C., Fabeiro, C. P., \& De Blas, X. P. (2005). Importância da celebração de eventos culturais para o turismo do Minho-Lima: Estudo de Caso. Revista Portuguesa de Estudos Regionais, 11, 61-76.

Richards, G. (2015). Developing the eventful city: Time, space and urban identity. In M. Al Muhairi, \& S. Mushatat (Eds.), Planning for event cities (pp. 37-46). Ajman, United Arab Emirates: Muncipality and Planning Department of Ajman.

Rocha, T. V., Katayama, N. H., Fuhrer, C., \& Cherubini, T. (2013). O efeito das ações culturais na imagem de marca e lealdade dos clientes no setor de telefonia móvel. Revista Produção Online, 13(2), 450-478. doi: 10.14488/1676-1901.v13i2.1000

Santos, J. F., Carvalho, R. \& Figueira, L. M. (2012). A importância do turismo cultural e criativo na imagem de um destino turístico. Revista Turismo \& Desenvolvimento, 3(7/18), 1559-1572. 
Sharif, B. \& Alimoradi, A. (2011). Toward the future tourism marketing. Journal of Basic and Applied Scientifie Research, 1(12), 2889-2899.

Silva, X. M. (2012). La organización de eventos como estrategia de comunicación y promoción del territorio en tiempos de crisis. El caso del Xacobeo 2010. Comunicação apresentada em III Congreso Internacional Asociacion Española de Investigacion da Comunicación, Tarragona.

Sousa, B. \& Ribeiro, I. (2018). City marketing e os eventos: Um estudo de caso aplicado ao Carnaval de Ovar. European Journal of Applied Business Management. Special Issue, 73-84.

Sousa, B. \& Vasconcelos, S. (2018). Branding territorial e o papel da imagem no comportamento do consumidor em turismo: O caso de Arouca. European Journal of Applied Business Management, Special Issue, 1-14.

Sousa, B. \& Simões, C. (2010). Comportamento e perfil do consumidor de turismo de nichos. TékhneRevista de Estudos Politécnicos, (14), 137-146.

Tinto Arandes, J. A. (2008). La imagen de marca de las ciudades. Provincia, 19, 91-121.

Torres, M. P. M. (2010). Citymarketing, la imagen y marca de una ciudad. Temas para la Educación Revista digital para profesionales de la enseñanza, 7, 1-7.

Trueman, M., Klemm, M. \& Giroud, A. (2004). Can a city communicate? Bradford as a corporate brand. Corporate Communications, 9(4), 317-330. doi: 10.1108/13563280410564057

Tsiotsou, R. \& Ratten, V. (2010). Future research directions in tourism marketing. Marketing Intelligence \& Planning, 28(4), 533-544. doi: 10.1108/02634501011053702

Umbelino, A. F. (2016). A importância de eventos culturais na promoção do território/região - O caso de estudo do Festival Músicas do Mundo. Estoril: Escola Superior de Hotelaria e Turismo do Estoril.

Vieira, J. M. (2015). Eventos e turismo - Planeamento e organização - Da teoria à prática. Lisboa: Edições Sílabo.

Winfield-Pfefferkorn, J. (2005). The branding of cities. Exploring city branding and the importance of brand image (unpublished Masters thesis). Syracuse University, United States of America.

MÁRIO ROLA é licenciado em gestão de atividades turísticas, desde 2015, pelo Instituto Politécnico do Cávado e do Ave (IPCA) onde concluiu no presente ano o mestrado em Gestão do Turismo. Desempenha a função de responsável de receção nos Hotéis do Bom Jesus SA. As suas áreas de interesse, enquanto investigador, centram-se no marketing aplicado aos destinos. Endereço institucional: Instituto Politécnico do Cávado e do Ave (IPCA), Escola Superior de Hotelaria e Turismo (ESHT), Campus do Instituto Politécnico, 4750-810 Barcelos, Portugal,

MARIA ALEXANDRA PEREIRA DA SILVA MALHEIRO é docente do Instituto Politécnico do Cávado e do Ave (IPCA) desde 1998, Professora Adjunta de Marketing e Estratégia da Escola Superior de Hotelaria e Turismo (ESHT) do Instituto Politécnico do Cávado e do Ave (IPCA), e é também diretora da ESHT desde 2017, momento da sua criação. É doutorada em Marketing e Estratégia pela Universidade do Minho, desde 2012, instituição onde também concluiu o Mestrado em Gestão de Empresas, em 2004 e a Licenciatura em Gestão de Empresas, em 1998. Participou em diversas conferências nacionais e internacionais como oradora e coautora de artigos e tem publicações em revistas nacionais e internacionais. É investigadora do CITUR e da UNIAG. A sua atividade pedagógica inclui a lecionação de unidades curriculares nas áreas do Marketing, Estratégia, de Marketing Turístico e Comportamento do consumidor, em cursos de $1 .^{\circ}$ e $2 .^{\circ}$ ciclo do IPCA. Endereço institucional: Instituto Politécnico do Cávado e do Ave (IPCA), Escola Superior de Hotelaria e Turismo (ESHT), Campus do Instituto Politécnico, 4750810 Barcelos, Portugal.

BRUNO SOUSA é professor no ensino superior desde 2009 e investigador nas áreas do Marketing, Estratégia e Turismo. É professor adjunto no Instituto Politécnico do Cávado e Ave (IPCA), onde exerce atualmente a Direção do Mestrado em Gestão do Turismo e Investigador CiTUR e UNIAG. É doutorado em Marketing e Estratégia pela Universidade do Minho em parceria com a Universidade de Aveiro e 
Universidade da Beira Interior (2014). Enquanto professor convidado na Universidade do Minho obteve o Prémio de Ensino da EEG U. Minho (2016), bem como o Best Thesis in Tourism Award na International Conference on Innovation and Entrepreneurship in Marketing and Consumer Behavior (2015). Licenciado em Gestão pela Universidade do Minho e Prémio Universidade do Minho (2001-2006). Desempenhou, anteriormente, a função de Analista de Mercados e de Cartão Cliente no Grupo Sonae, bem como a de Assistente de Marketing na Global Media Group SGPS, SA (jornal O JOGO). Endereço institucional: Instituto Politécnico do Cávado e do Ave (IPCA), Escola Superior de Hotelaria e Turismo (ESHT), Campus do Instituto Politécnico, 4750-810 Barcelos, Portugal.

Submetido em 9 abril 2018

Aceite em 20 outubro 2018 